\title{
A nanohybrid system for taste masking of sildenafil
}

This article was published in the following Dove Press journal:

International Journal of Nanomedicine

23 March 2012

Number of times this article has been viewed

\section{Ji-Hee Lee ${ }^{1, *}$ \\ Goeun Choil,* \\ Yeon-Ji Oh' \\ Je Won Park' \\ Young Bin Choy ${ }^{3}$ \\ Mung Chul Park' \\ Yeo Joon Yoon' \\ Hwa Jeong Lee ${ }^{2}$ \\ Hee Chul Chang ${ }^{4}$ \\ Jin-Ho Choy'}

'Center for Intelligent Nano-Bio Materials (CINBM), Department of Bioinspired Science and Department of Chemistry and Nano Science, ${ }^{2}$ Division of Life and Pharmaceutical Sciences and College of Pharmacy, Ewha Womans University, Seoul, Korea; ${ }^{3}$ Department of Biomedical Engineering, College of Medicine and Institute of Medical and Biological Engineering, Medical Research Center, Seoul National University, Seoul, Korea; ${ }^{4}$ Global Strategy Center and Pharmaceutical Research Institute, Daewoong Pharmaceutical Co., Ltd., Seoul, Korea

*These authors contributed equally to this work
Correspondence: Jin-Ho Choy Center for Intelligent Nano-Bio Materials (CINBM), Department of Bioinspired Science and Department of Chemistry and Nano Science, Ewha Womans University, I20-750, Seoul, Korea

Tel +82 232774305

Fax +82 232774340

Email jhchoy@ewha.ac.kr
Abstract: A nanohybrid was prepared with an inorganic clay material, montmorillonite (MMT), for taste masking of sildenafil (SDN). To further improve the taste-masking efficiency and enhance the drug-release rate, we coated the nanohybrid of SDN-MMT with a basic polymer, polyvinylacetal diethylaminoacetate (AEA). Powder X-ray diffraction and Fourier transform infrared experiments showed that SDN was successfully intercalated into the interlayer space of MMT. The AEA-coated SDN-MMT nanohybrid showed drug release was much suppressed at neutral $\mathrm{pH}$ (release rate, $4.70 \pm 0.53 \%$ ), suggesting a potential for drug taste masking at the buccal cavity. We also performed in vitro drug release experiments in a simulated gastric fluid $(\mathrm{pH}=1.2)$ and compared the drug-release profiles of AEA-coated SDN-MMT and Viagra ${ }^{\circledR}$, an approved dosage form of SDN. As a result, about 90\% of SDN was released from the AEAcoated SDN-MMT during the first 2 hours while almost $100 \%$ of drug was released from Viagra $^{\circledR}$. However, an in vivo experiment showed that the AEA-coated SDN-MMT exhibited higher drug exposure than Viagra ${ }^{\circledR}$. For the AEA-coated SDN-MMT, the area under the plasma concentration-time curve from 0 hours to infinity $\left(\mathrm{AUC}_{0-\infty}\right)$ and maximum concentration $\left(\mathrm{C}_{\max }\right)$ were $78.8 \pm 2.32 \mu \mathrm{g} \cdot$ hour $/ \mathrm{mL}$ and $12.4 \pm 0.673 \mu \mathrm{g} / \mathrm{mL}$, respectively, both of which were larger than those obtained with Viagra ${ }^{\circledR}\left(\mathrm{AUC}_{0-\infty}=69.2 \pm 3.19 \mu \mathrm{g} \cdot \mathrm{hour} / \mathrm{mL} ; \mathrm{C}_{\max }=10.5 \pm 0.641 \mu \mathrm{g} / \mathrm{mL}\right)$. Therefore, we concluded that the MMT-based nanohybrid is a promising delivery system for taste masking of SDN with possibly improved drug exposure.

Keywords: montmorillonite, nanohybrids, polyvinylacetal diethylaminoacetate, sildenafil citrate, taste masking

\section{Introduction}

There have been many attempts to explore new nanohybrids with the desired physicochemical and biological properties, such as inorganic-organic nanohybrids with two-dimensional limited high-temperature superconductivity, ${ }^{1}$ bio-inorganic nanohybrids with enhanced gene delivery characteristics, ${ }^{2-4}$ intravenous injectable drug-delivery systems, ${ }^{5}$ and various therapeutic agent-delivery systems with high efficiency. ${ }^{6-13}$ Among various inorganic nanohybrids, the most widely studied for pharmaceutical application were smectite clays as formulation additives. For taste masking in this study, we employed a smectite clay material that can swell and encase a drug.

The unpleasant taste of drugs has been one of the major limitations for designing oral drug formulations since swallowing a tablet may be the only option for the drug to bypass taste perception in the buccal cavity. However, such methods for drug administration still require the patients' cooperation to a large extent and may be inconvenient, especially for drugs needing punctual or sudden dosing schedules. 
For this reason, sildenafil (SDN) citrate may be a drug that needs a delivery strategy other than a tablet formulation for swallowing. SDN, an inhibitor of cyclic guanosine monophosphate-specific phosphodiesterase type 5, has been used for treatment of erectile dysfunction and is already approved as a tablet dosage form for oral delivery (Viagra ${ }^{\circledR}$; Pfizer, New York, NY). The nature of this specific drug therapy implies that the dosing moments are mostly unexpected or sudden, and for patient convenience, an easier administration method other than swallowing is needed. Redesigns of the formulations, such as chewable or dissolvable tablets, ${ }^{14-17}$ or rapidly dissolving film, ${ }^{18-20}$ would be desirable, but may not be practical for SDN delivery due to its unpleasant taste. ${ }^{21}$

Therefore, taste masking of SDN may be needed for orally disintegrating formulations to ensure patient compliance and improve acceptability of medication. Previously, numerous attempts have been made in the field of taste masking, where most approaches were based on encapsulation of drugs with polymeric materials, such as cellulose, Eudragit ${ }^{\circledR}$ (Evonik Industries AG, Essen, Germany), or polyethylene glycol, among others. ${ }^{22-24}$ The purpose of encapsulation was primarily focused on suppressed release of drugs in biological fluids with no (or almost no) free drug molecules available at the buccal cavity. However, for those conventional approaches, the diffusion barrier formed by polymeric materials would still be in effect while the formulations pass through the gastrointestinal tract, where the drug release would be undesirably suppressed. This is not beneficial, especially for SDN delivery, since the drug requires rapid systemic absorption for its own therapeutic purpose. To resolve this problem, the delivery profile of SDN should be specifically tailored: the drug release should be highly suppressed at the buccal cavity and then released rapidly in the gastrointestinal fluid.

Some previous studies utilized polymers with $\mathrm{pH}-$ dependent solubility as an encapsulant, where the barrier polymer dissolves only at low $\mathrm{pH}$, with controlled release of the drug in the gastric cavity, not in the buccal cavity. ${ }^{25-27}$ Although this selective delivery profile may benefit from both taste masking and rapid drug release to some extent, the formulations may not yet be optimized for the following reasons. The drug molecules may be distributed on the surface of the polymeric encapsulant slightly, which may still cause a bitter taste. The delayed dissolution of polymers may still inhibit rapid onset of drug release and the systemic absorption of drugs may be retarded altogether.

In this study, we prepared a bentonite-based nanohybrid coated with an acid-soluble polymer to better achieve both taste masking and rapid delivery of SDN. Bentonite, mainly composed of montmorillonite (MMT), consists of tetrahedral sheets of $\mathrm{SiO}_{4}$ units and octahedral sheets of $\mathrm{Al}^{3+}$ ions. ${ }^{28,29}$ The isomorphous substitution of $\mathrm{Al}^{3+}$ with $\mathrm{Mg}^{2+}$ can generate a negative surface charge on bentonite. To balance the excess negative charge, the interlayer cations are stabilized within the layers and as a result, bentonite possesses cation-exchange capacity (CEC). Therefore, the cationic drug SDN could be encased in the layered space of MMT with strong ionic bonding, producing an SDN-MMT nanohybrid with taste-masking functionality. The nanohybrid was also coated with an acidsoluble polymer, polyvinylacetal diethylaminoacetate (AEA), to further prevent drug release in the buccal cavity and aid rapid release in the stomach. For the latter, we reported that the presence of a large molecule possessing the same polarity as the intercalated compound facilitated the diffusion of the intercalated compound by enlarging the entrance of layered structures of MMT. ${ }^{30-32}$ The carrier material, MMT clay, employed in this work is approved by the US Food and Drug Administration (FDA) as a diluting agent for oral delivery and is widely used in medicine and pharmacology. ${ }^{33,34}$ The polymer used for coating, AEA, is also accepted as a food additive by the FDA. ${ }^{35}$

In this study, we developed an SDN-MMT nanohybrid with taste-masking functionality and compared its drug-release profile with that of Viagra ${ }^{\circledR}$, an SDN medication available on the market. We aimed to prove that our SDN-MMT nanohybrid formulation was advantageous in its therapeutic efficacy as well as in administration strategy. Our SDN-MMT nanohybrid was characterized with powder X-ray diffraction (PXRD), Fourier transform infrared (FT-IR) spectra, and thermogravimetry (TG) analysis to examine the properties of SDN intercalated in MMT. The release profiles of SDN with both noncoated and AEA-coated SDN-MMT nanohybrids were also examined in simulated biological fluids, using high-performance liquid chromatography (HPLC). To assess the drug bioavailability, the SDN-MMT formulations were compared with Viagra ${ }^{\circledR}$ through both in vitro and in vivo experiments.

\section{Material and methods Materials}

Montmorillonite (MMT, Kunipia-F; $\mathrm{CEC}=110$ mequiv/100 g) and polyvinylacetal diethylaminoacetate (AEA) were obtained from Kunimine Industries Co, Ltd (Tokyo, Japan) and Sankyo (Tokyo, Japan), respectively and used without further purification. Sildenafil (SDN) was a kind gift from Daewoong (Seoul, Korea). Acetonitrile, methanol, and glacial acetic acid of high performance liquid chromatography (HPLC) grade were purchased from JT Baker (Cleveland, $\mathrm{OH}$ ). 


\section{Preparation of SDN-MMT and AEA-coated SDN-MMT}

The SDN-MMT nanohybrid was prepared by ion exchange reaction. Briefly, $20 \mathrm{~g}$ MMT was dispersed in $2 \mathrm{~L}$ deionized water for 3 hours at room temperature to give a $1.0 \mathrm{wt} \%$ MMT suspension. To prepare an SDN solution, $14.7 \mathrm{~g}$ SDN, which is equivalent to the CEC of $20 \mathrm{~g}$ MMT, was first dissolved in $1200 \mathrm{~mL}$ of a $1 \%$ phosphoric acid solution, and $800 \mathrm{~mL}$ ethanol was added afterwards. The resulting solution was then mixed with the MMT suspension and stirred for 4 hours at room temperature to facilitate an ion exchange reaction. The solid product, SDN-MMT, was then filtered and washed twice with 50\% ethanol solution and pure ethanol, respectively, to remove the residual drug. The resulting SDN-MMT slurry (200 g) was dispersed again in a mixture of methylene chloride (MC) and ethanol (MC: ethanol, $200 \mathrm{~mL}: 400 \mathrm{~mL}, \mathrm{v} / \mathrm{v}$ ) and spray-dried with an SD-1000 spray dryer (Eyela, Tokyo, Japan) under the following conditions: inlet temperature, $80^{\circ} \mathrm{C}$; blower speed, $0.30 \mathrm{~m}^{3} /$ minute, and atomizing pressure, $125 \pm 5 \mathrm{kPa}$.

To prepare the AEA-coated SDN-MMT, the SDNMMT slurry (200 g) was dispersed in a mixture of MC and ethanol (MC: ethanol, $200 \mathrm{~mL}: 400 \mathrm{~mL}, \mathrm{v} / \mathrm{v}$ ), where $10 \mathrm{~g}$ AEA was dissolved. The resulting suspension was then spray-dried with a spray dryer under the same conditions stated above.

\section{Characterization of nanohybrids}

The PXRD patterns of both SDN-MMT and AEA-coated SDN-MMT were collected using a Rigaku D/MAX-2200 Ultima diffractometer (Rigaku International Corporation, Tokyo, Japan) equipped with Ni-filtered $\mathrm{Cu}-\mathrm{K} \alpha$ radiation $(\lambda=1.5418 \AA)$. The patterns were recorded at $40 \mathrm{kV}$ and $30 \mathrm{~mA}$. TG analysis was performed at a heating rate of $5^{\circ} \mathrm{C} /$ minute from room temperature to $1000^{\circ} \mathrm{C}$ under ambient atmosphere (SDT Q600; TA Instruments, New Castle, DE). FT-IR spectra (Figure S1) were recorded with a JASCO FT/ IR-6100 spectrophotometer (JASCO, Easton, MA) by the standard $\mathrm{KBr}$ disk method. The particle size (Figure S2) of SDN-MMT and AEA-coated SDN-MMT were obtained with dynamic light-scattering method (ZetaSizer; Nano ZetaSizer, Malvern Instruments, Malvern, UK).

\section{Determination of SDN content}

To determine the amount of SDN, SDN needs to be completely extracted from the SDN-MMT nanohybrids. Thus, the solution was first prepared with an aqueous solution buffered at $\mathrm{pH} 4.5\left(\mathrm{KH}_{2} \mathrm{PO}_{4}\right)$, acetonitrile and phosphoric acid
(400:600:1, v/v/v). Then, each of the samples containing the equivalent amount of $6 \mathrm{mg} \mathrm{SDN}$ was dispersed in $100 \mathrm{~mL}$ of the resulting solution and sonicated for 40 minutes. The suspension was filtered by a polypropylene membrane with a pore size of $0.45 \mu \mathrm{m}$ (Pall, Port Washington, NY), which was then measured with HPLC (1100 Series Instrument; Agilent Technologies, Santa Clara, CA) using a column, Zorbax Eclipse XDB-C18 (4.6 mm $\times 250$ mm, $5 \mu \mathrm{m}$; Agilent Technologies). The mobile phase was prepared with an aqueous solution buffered at $\mathrm{pH} 4.5\left(\mathrm{KH}_{2} \mathrm{PO}_{4}\right)$ and acetonitrile $(40: 60, \mathrm{v} / \mathrm{v})$. The samples were analyzed under the following conditions: flow rate, $1 \mathrm{~mL} /$ minute; injection volume, $10 \mu \mathrm{L}$; column temperature, $35^{\circ} \mathrm{C}$; and UV wavelength, $230 \mathrm{~nm}$.

\section{In vitro drug release experiment}

The in vitro drug release tests were conducted with intact SDN, SDN-MMT, AEA-coated SDN-MMT, and Viagra ${ }^{\circledR}$, following the paddle-stirring method using a DST-810 dissolution tester (LabFine, Seoul, Korea). ${ }^{36}$ The bath temperature was maintained at $37^{\circ} \mathrm{C} \pm 0.5^{\circ} \mathrm{C}$ and the impeller was set at $50 \mathrm{rpm}$. Each sample containing the equivalent amount of $50 \mathrm{mg}$ SDN was dissolved in $900 \mathrm{~mL}$ of the release media, the aliquot of which was sampled at scheduled intervals. The aliquot was then filtered with a polypropylene membrane with a pore size of $0.45 \mu \mathrm{m}$ (Pall), which was measured with the HPLC as described above in 'Determination of SDN content'. In this work, two distinct release media were employed to simulate the buccal and gastric cavities, respectively. To simulate the buccal condition and evaluate the taste-masking ability of the nanohybrids, the release test was performed at neutral $\mathrm{pH}$ for 2 minutes, following the International Pharmaceutical Federation/American Association of Pharmaceutical Sciences guidelines. ${ }^{37}$ To simulate the gastric conditions, the release test was performed at $\mathrm{pH} 1.2$ for 2 hours.

\section{In vivo experiment}

\section{Preparation of standard solutions and animals}

The stock solution of SDN was prepared at a concentration of $50 \mu \mathrm{g} / \mathrm{mL}$ in methanol and was further diluted to $0.1 \sim 4.0 \mu \mathrm{g} / \mathrm{mL}$ for plasma calibration standards. The solutions of six different concentrations, covering the expected ranges of 2 200 ng/mL, were prepared. Six male beagle dogs, 8.5 months old and weighing 12 15 kg, were purchased from Central Lab Animal (Seoul, Korea). The animals were fasted overnight with free access to water. Viagra ${ }^{\circledR}$ or AEA-coated SDN-MMT was orally administered to each dog at a dose of $20 \mathrm{mg} / \mathrm{kg}(\mathrm{n}=3)$. The SDN dose was selected on the basis 
of the pharmacological and pharmacokinetic data published previously. ${ }^{38}$ The Viagra ${ }^{\circledR}$ tablets were ground into powder, which was weighed to match the dose of SDN. OASIS HLB 96-well plates (10 mg; Waters Corporation, Milford, MA) were utilized for solid-phase extraction (SPE) of the analytes in plasma samples. In all instances, animals were humanely handled in accordance with Institutional Animal Care and Use Committee guidelines.

\section{Analytical method development \\ Blood sampling and HPLC-ESI-MS/MS analyses}

Approximately $5 \mathrm{~mL}$ of blood was collected from a right front leg vein at $0.25,0.5,1,2,3,4,6,8,12,16$, and 24 hours after oral dosing. The cannula was filled with heparinized saline (500 IU mL $\mathrm{L}^{-1}$ ) to prevent blood clotting, and then the blood samples were taken after centrifugation and stored at $-70^{\circ} \mathrm{C}$ until analysis.

An OASIS HLB 96-well SPE plate (Waters Corporation) was used for the extraction of the analyte from the plasma samples. Aliquots of $200 \mu \mathrm{L}$ of $6 \%$ perchloric acid were added into the $300 \mu \mathrm{L}$ of blank or plasma sample in a $1.5 \mathrm{~mL}$ microtube to precipitate the protein. The mixture was vortexed for 10 seconds, then centrifuged at $15,000 \times \mathrm{g}$ for 10 minutes. The supernatant was immediately loaded onto each well of OASIS HLB plate, previously conditioned with $600 \mu \mathrm{L}$ of methanol followed by $600 \mu \mathrm{L}$ of water. The whole wells were washed with $600 \mu \mathrm{L}$ of water and then airdried for about 30 seconds. The attached analyte was eluted twice with $200 \mu \mathrm{L}$ of $5 \%$ methanolic ammonium hydroxide (conc $\mathrm{NH}_{4} \mathrm{OH} /$ methanol, 5:95, v/v), then evaporated to dryness at room temperature by vacuum centrifugation. The residues were reconstituted to $200 \mu \mathrm{L}$ with methanol, and a twentieth $(10 \mu \mathrm{L})$ of the solution was subjected to HPLCelectrospray ionization mass spectrometry/mass spectrometry (ESI-MS/MS) analysis.

All HPLC-ESI-MS/MS experiments were carried out using a Waters/Micromass Quattro micro/MS interface consisting of a Waters 2695 separation module connected directly to a Micromass Quattro micro/MS (Waters Corporation). Separation was performed on a $30 \mathrm{~mm} \times 2.1 \mathrm{~mm}$ Xterra MS C18 (3.5 $\mu \mathrm{m}$; Waters Corporation) reversed-phase column. The analytes were eluted at a flow rate of $180 \mu \mathrm{L} /$ minute with an isocratic system of $24 \%(\mathrm{v} / \mathrm{v})$ aqueous acetonitrile with $0.1 \%$ acetic acid for 7 minutes. The column effluent was directed to the ESI-MS, which was operated in the positive ion mode without splitting. The instrument was tuned by the direct infusion of a stock solution of SDN $(2 \mu \mathrm{g} / \mathrm{mL}$ in methanol $)$ in the ion source at $40 \mu \mathrm{L} /$ minute. The optimization parameters of the ESI-MS/MS system were based on the maximum generation, first of the protonated molecular (parent) ions, and then of the corresponding fragment (product) ions. The following tuning parameters were retained for the optimum ESI-MS/MS detection of SDN: the capillary voltage and cone voltage were $2 \mathrm{kV}$ and $35 \mathrm{~V}$, respectively; the source and desolvation temperatures were $130^{\circ} \mathrm{C}$ and $250^{\circ} \mathrm{C}$, respectively; the desolvation gas and cone gas flow rates were $500 \mathrm{~L} /$ hour and $50 \mathrm{~L} /$ hour, respectively. The collision energy in the MS/MS mode, concurring with full argoninduced fragmentation of the parent molecules, was found to be $0.27 \mathrm{~V}$. The quantification of SDN was conducted using MS/MS in multiple reaction monitoring (MRM) mode. This was done by choosing the two mass ions set to detect a transition of the parent ion to the product ion specific to SDN (474.7 > 99.9). The molecular structures and major fragmentation pattern for SDN are shown in Figure 1.

\section{HPLC-ESI-MS/MS analytical method validation}

for SDN in in vivo samples

Linearity of calibration was assessed by analyzing six standards ranging from $2 \sim 200 \mathrm{ng} / \mathrm{mL}$ in plasma. The calibration curve was based on drug peak area and was analyzed by weighted linear regression using the Sigmaplot program (v. 8.0; SPSS Inc, Chicago, IL). The correlation coefficient was calculated. The limit of quantification (LOQ) was defined as the drug concentration producing at least ten times the response compared to the blank response $(\mathrm{S} / \mathrm{N}>10)$. Quality control (QC) samples were prepared at low $(5 \mathrm{ng} / \mathrm{mL})$, medium $(50 \mathrm{ng} / \mathrm{mL})$, and high concentration $(150 \mathrm{ng} / \mathrm{mL})$ in the same way as the plasma calibration samples. Intra- and Interday precision and accuracy were assessed by analyzing the above-mentioned QC samples with five replicates on three different days, and they were presented as relative standard deviations (RSD). Recoveries of the analytes spiked into plasma samples at three different concentrations $(2,20$, and $100 \mathrm{ng} / \mathrm{mL})$ were calculated by comparing the peak area of the extracted sample to that of the unextracted standard solution prepared with the same solvent, and each experiment at the same concentrations was done in triplicate. Stability of SDN was conducted using QC samples after three freeze-thaw cycles, at room temperature, and after post-preparation procedures.

\section{Pharmacokinetic study}

Pharmacokinetic parameters were determined from the plasma SDN concentration-time data by noncompartmental analysis using WinNonlin Professional software (v. 2.0; 


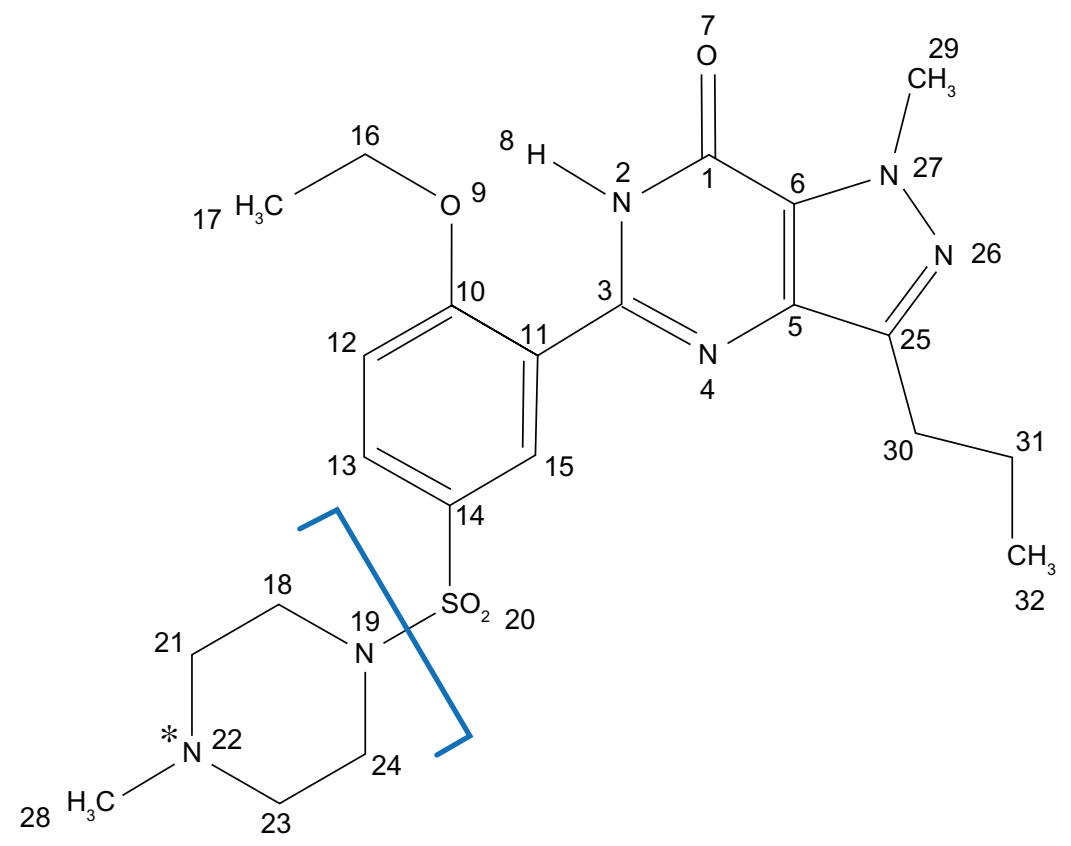

Figure I Chemical structure of sildenafil and its electrospray ionization mass spectrometry/mass spectrometry fragmentations.

Note: *Protonation site.

Pharsight Co, Mountain View, CA). The pharmacokinetic parameters estimated from the data were area under the plasma concentration-time curve from 0 hours to infinity $\left(\mathrm{AUC}_{0-\infty}\right)$, elimination half-life $\left(\mathrm{t}_{1 / 2}\right)$, apparent volume of distribution $\left(\mathrm{V}_{\mathrm{d}} / \mathrm{F}\right)$, and total clearance $(\mathrm{Cl} / \mathrm{F})$. The maximum plasma concentration $\left(\mathrm{C}_{\max }\right)$ and the time required to reach $\mathrm{C}_{\max }\left(\mathrm{T}_{\max }\right)$ were determined from the individual plasma concentration-time curve by visual inspection.

\section{Statistical analysis}

All the results were presented as means \pm standard deviations. An unpaired Student's $t$-test was used to determine significant differences between the SDN and AEA-coated nanohybrid data. Differences were considered to be significant when $P<0.05$.

\section{Stability test}

The shelf-life of SDN for SDN-MMT and AEA-coated SDN-MMT nanohybrids were examined through an accelerated stability test. ${ }^{39}$ Each of the samples was put in a glass vial and sealed, which was then placed in a constant temperature and humidity chamber (LH-1000; New Power Engineering, Seoul, Korea) for 6 months. The temperature and humidity were maintained at $40^{\circ} \mathrm{C}$ and $75 \%$, respectively. The amount of nondegraded SDN was measured with HPLC as described above in "Determination of SDN content". For each of the samples, the fraction of nondegraded SDN was calculated by percentage based on the SDN content measured initially before the stability test.

\section{Results and discussion Powder X-ray diffraction analysis}

Figure 2 shows the PXRD patterns of intact SDN, pristine MMT, SDN-MMT, and AEA-coated SDN-MMT. For pristine MMT, the characteristic peak of (001) was clearly seen at $6.9^{\circ}$ (Figure 2B), which was shifted to $3.8^{\circ}$ for both SDN-MMT and AEA-coated SDN-MMT nanohybrids (Figure 2C and D). This could be ascribed to the expanded basal spacing of MMT from $12.5 \AA$ to $22.8 \AA$ after intercalation of SDN. There was no difference in the PXRD patterns between the SDN-MMT and the AEA-coated SDN-MMT nanohybrids, implying that SDN still resided in the interlayer space of the MMT after the AEA coating. The peaks of intact SDN (namely, crystalline SDN) were not observed with SDN-MMT and AEA-coated SDN-MMT nanohybrids, indicating that SDN molecules were distributed in the MMT interlayer space with a molecular level as reported previously in other nanohybrid systems. ${ }^{32,40}$

Subtracting the layer thickness of MMT (9.3 $\AA$ ) from the basal spacing of SDN-MMT, the gallery height was estimated to be $13.5 \AA$. Considering that the longitudinal and lateral molecular dimension of SDN are $5 \AA$ and $16 \AA$, respectively, it became very likely that the SDN molecules should be stabilized in a double-layer arrangement. To 


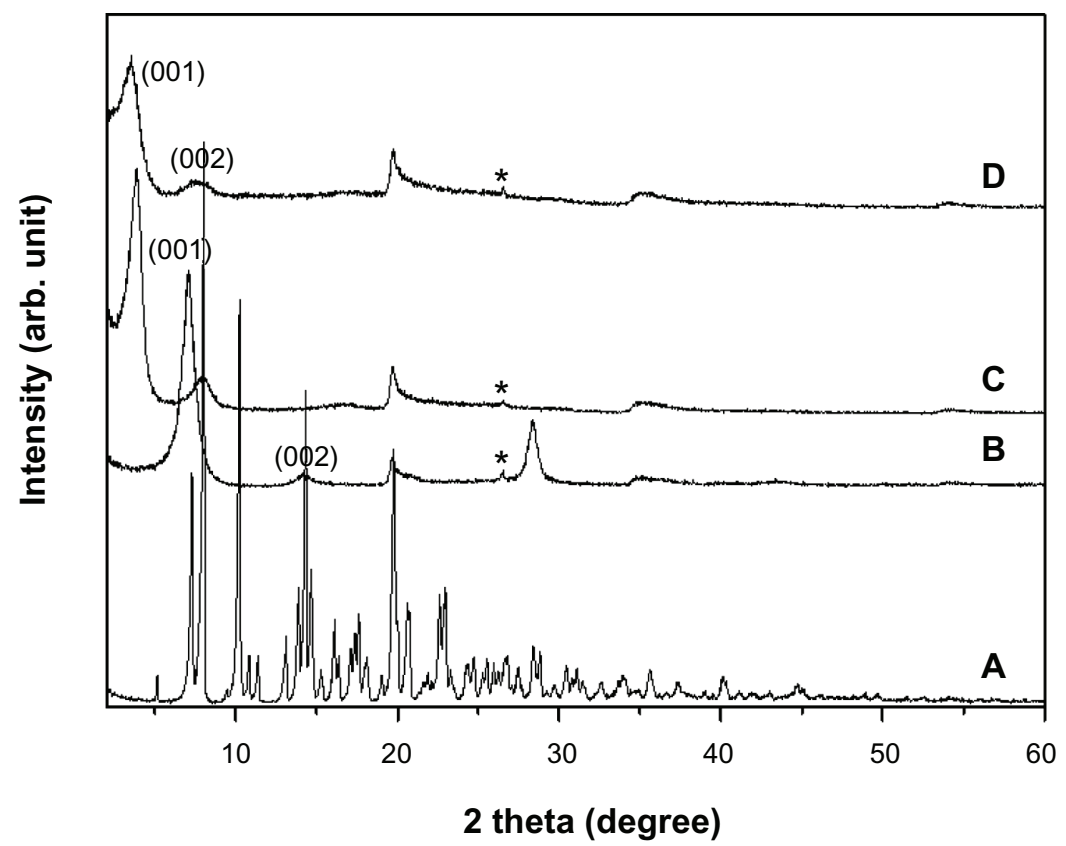

Figure 2 Powder X-ray diffraction patterns of (A) sildenafil citrate, (B) montmorillonite (MMT), (C) sildenafil-montmorillonite (SDN-MMT), and (D) polyvinylacetal diethylaminoacetate (AEA)-coated SDN-MMT.

Note: *Quartz.

explain this, the steric limitations between the intercalated SDN and charged sites of MMT layers were examined. The steric limitations are generally expressed by the equivalent area $\left(\mathrm{A}_{\mathrm{e}}\right)$ of clay lattices and the area demand $\left(A_{c}\right)$ of intercalated molecules. The $A_{e}$ can be estimated from the equation $A_{e}=a b / 2 \xi$, where $a$ and $b$ are lattice parameters and $\xi$ is the layer charge. The $A_{e}$ of MMT was estimated to be $28.85 \AA^{2}$, calculated using a negative charge density, $0.27 \mathrm{e}^{-/ 46.5} \AA^{2}{ }^{41}$ The area demand ( $\mathrm{A}_{c}$ ) of SDN was about $136 \AA^{2}$, calculated from the molecular model in Figure 3B. Thus, since $A_{c}$ is larger than $2 A_{e}, S D N$ molecules should have a tilted bilayer arrangement to avoid steric hindrance. ${ }^{31,42}$ The protonation sites of SDN should be only at N22 as shown in Figure 1 since protonation in combined rings of pyrimidine and pyrazole is unlikely due to resonance and steric effects. ${ }^{43}$ As a result, the SDN
A

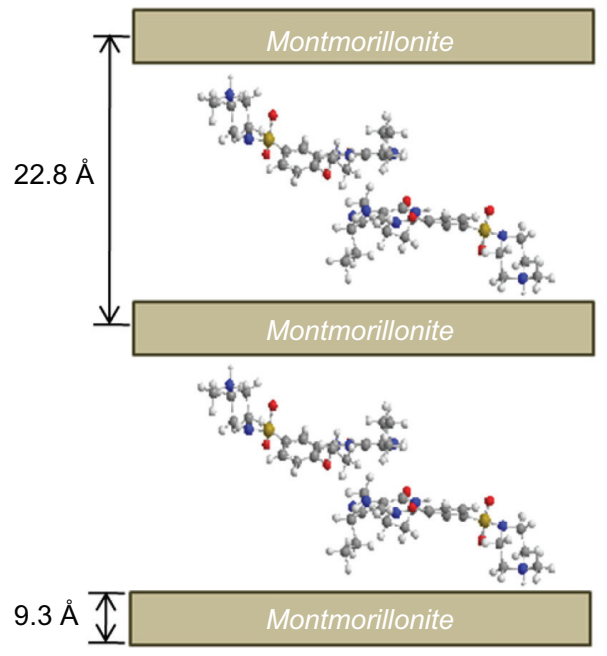

B
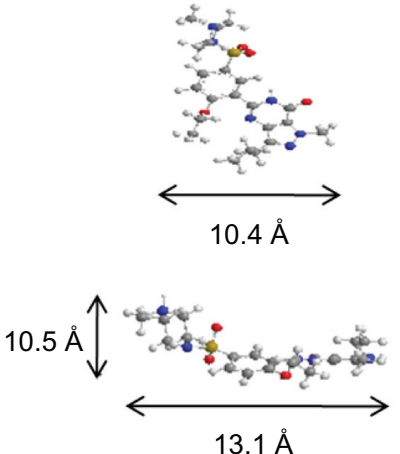

Figure 3 Schematic descriptions for (A) sildenafil-montmorillonite (SDN-MMT) and (B) sildenafil (SDN) molecules drawn by ChemBio3D Ultra I2.0 program (Cambridge Soft, Cambridge, MA).

Notes: carbon, gray; nitrogen, blue; oxygen, red; sulfur, yellow; hydrogen, white. 
molecules should be arranged in the interlayer space of MMT as depicted in Figure 3A.

\section{Thermogravimetric analysis}

Figure 4 depicts the TG curves of pristine MMT, intact SDN, and SDN-MMT. For pristine MMT, the first weight loss up to $100^{\circ} \mathrm{C}$ was due to the evaporation of water adsorbed on the MMT surface (Figure 4C). The weight loss observed at $600^{\circ} \mathrm{C}$ was attributed to dehydroxylation and phase transition of MMT. The intact SDN exhibited three consecutive weight losses (Figure 4A). The first weight loss at $188^{\circ} \mathrm{C}$ was due to the decomposition of citrate and the second weight loss at $270^{\circ} \mathrm{C}$ was ascribed to the decomposition of the SDN molecule itself. The intact SDN was completely decomposed above $326^{\circ} \mathrm{C}$, corresponding to the last weight loss. For SDN-MMT (Figure 4B), the weight loss due to dehydration was seen up to $200^{\circ} \mathrm{C}$. The following weight loss from $250^{\circ} \mathrm{C}$ to $750^{\circ} \mathrm{C}$ was due to the decomposition of intercalated SDN. Interestingly, the decomposition temperature of SDN in the nanohybrid $\left(250^{\circ} \mathrm{C}\right)$ was lower than that of intact SDN $\left(270^{\circ} \mathrm{C}\right)$.This result could be due to the molecular distribution of SDN upon intercalation, which would possibly lead to the enhancement of SDN solubility. ${ }^{31,44}$

\section{SDN content in nanohybrids}

The SDN content of the SDN-MMT and AEA-coated SDN-MMT nanohybrids was $30.61 \% \pm 0.55 \%$ and

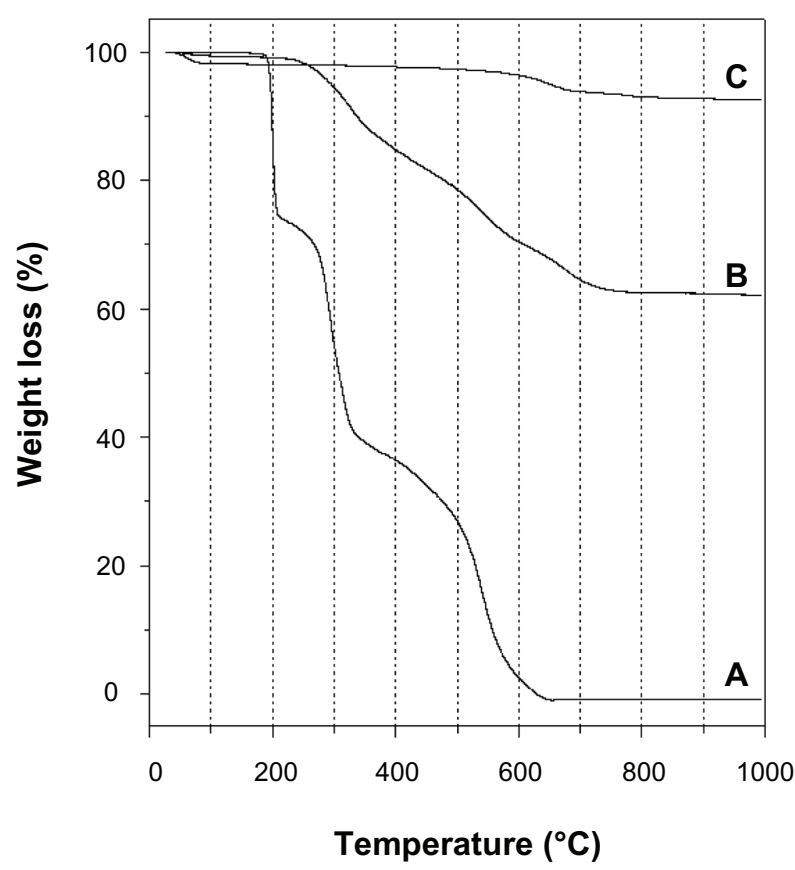

Figure 4 Thermogravimetric curves of (A) sildenafil citrate, (B) sildenafilmontmorillonite (SDN-MMT), and (C) montmorillonite (MMT).
$16.59 \% \pm 0.44 \%$, respectively. The decrease in SDN content with AEA-coated SDN-MMT was due to incorporation of the AEA polymer through the coating process employed in this work (MMT:AEA = 1:1 w/w).

\section{In vitro drug release test}

We prepared our nanohybrid system to mask the taste of SDN. To assess this quality, we conducted an in vitro drug-release experiment in deionized water for 2 minutes, mimicking the condition in the buccal cavity. ${ }^{37}$ As shown in Table 1, for intact SDN, more than $73 \%$ of the drug was dissolved rapidly into the release media as expected. Almost half of SDN was released from Viagra ${ }^{\circledR}$ during the first 2 minutes since the tablet is designed to rapidly release the drug in the biological fluid. In contrast, the nanohybrids (ie, SDN-MMT and AEA-coated SDN-MMT) exhibited greatly suppressed release under the test condition employed in this work. The SDN release from the nanohybrids was more than tenfold less than that from intact SDN and Viagra ${ }^{\circledR}$ : the SDN-MMT exhibited no release, and for AEA-coated SDN-MMT, only a slight portion of the drug $(<5 \%)$ was released during the first 2 minutes. The strong ionic interaction between the SDN molecules and the MMT interlayers appeared to hinder freeing the drug molecules, resulting in very low drug release. A slight drug release $(<5 \%)$ from AEA-coated SDN-MMT could be due to slight dissolution and ionization of the AEA even in the neutral media to deintercalate the drug in the MMT to some extent.

In addition to taste masking, the SDN needs to be released rapidly in the gastric cavity for satisfactory therapeutic efficacy. Thus, we examined the drug-release profiles of SDN-MMT and AEA-coated SDN-MMT nanohybrids in a simulated gastric condition and compared them with those of intact SDN and Viagra ${ }^{\circledR}$ (Figure 5; Table S4). The drug release from intact SDN and Viagra ${ }^{\circledR}$ was very rapid as expected. More than $90 \%$ of SDN was released in 10 minutes and $99 \%$ during the first 2 hours, which could be attributed to high solubility of SDN in acidic fluid. ${ }^{45}$ However, the drug

Table I In vitro drug dissolution profiles under a simulated buccal condition

\begin{tabular}{lll}
\hline Samples & \multicolumn{2}{c}{ \% drug release } \\
\cline { 2 - 3 } & I minute & 2 minutes \\
\hline Viagra $^{\circledR}$ & $17.17 \pm 4.2$ & $48.78 \pm 5.49$ \\
Sildenafil citrate & $53.31 \pm 7.47$ & $73.66 \pm 4.6 \mathrm{I}$ \\
Noncoated nanohybrid & 0.00 & 0.00 \\
AEA-coated nanohybrid & $0.66 \pm 0.64$ & $4.70 \pm 0.53$ \\
\hline
\end{tabular}

Notes: ${ }^{a}$ Values are mean $\pm S D ; n=3$.

Abbreviations: AEA, polyvinylacetal diethylaminoacetate; SD, standard deviation. 


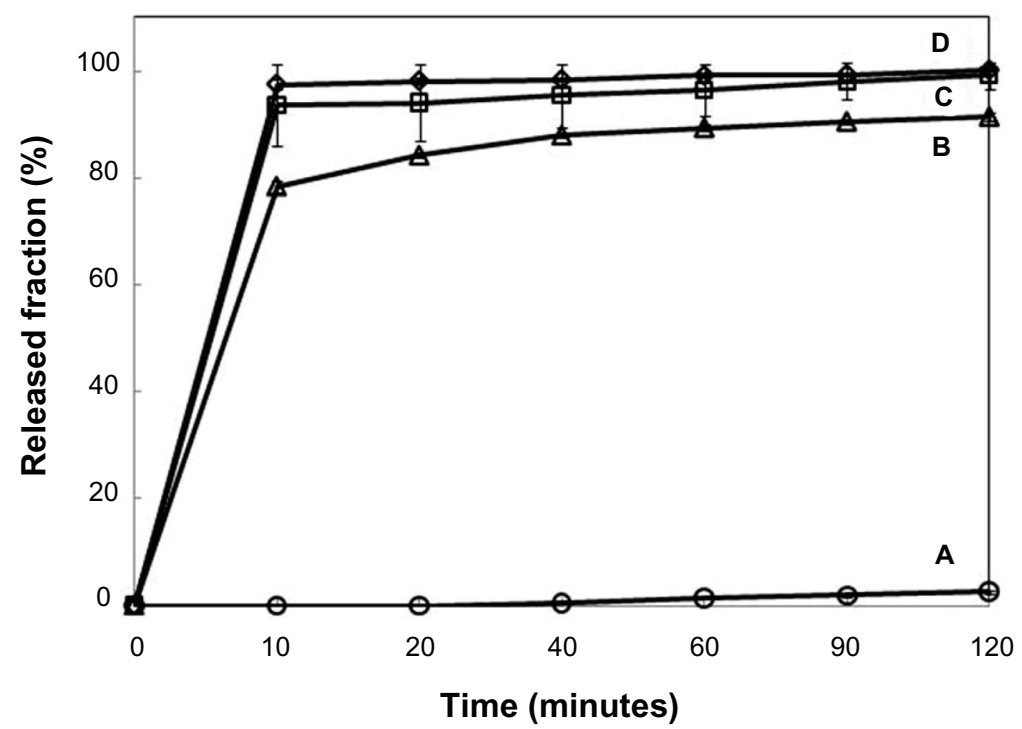

Figure 5 Release profiles of sildenafil from (A) sildenafil-montmorillonite (SDN-MMT), (B) polyvinylacetal diethylaminoacetate (AEA)-coated SDN-MMT, (C) Viagra ${ }^{\circledR}$, and (D) sildenafil citrate.

Note: The release experiments were performed at $\mathrm{pH}=\mathrm{I} .2$.

was hardly released from SDN-MMT $(<3 \%)$ again due to the strong ionic interaction between the intercalated SDN and MMT. In spite of its excellent taste-masking properties (Table 1; Table S3), the SDN-MMT by itself may not be useful for effective delivery of SDN. On the other hand, drug release increased dramatically with the AEA-coated SDN-MMT nanohybrid. About $75 \%$ of SDN was released in 10 minutes and up to $90 \%$ during the first 2 hours, which was only $10 \%$ less than Viagra ${ }^{\circledR}$. The cationic macromolecule, AEA, when dissolved and ionized selectively at low $\mathrm{pH}$, could replace the intercalated drug molecules effectively and enlarge the interlayer spacing to facilitate drug diffusion out towards the release media. ${ }^{31}$ This result is meaningful in a sense that AEA-coated SDN-MMT nanohybrids could provide both taste masking and effective in vitro release of SDN relatively similar to proven medications like Viagra ${ }^{\circledR}$.

\section{SDN analytical method validation}

Under the HPLC-ESI-MS/MS conditions described in the experimental section, no interfering peak was detected in the plasma samples. MRM in a positive mode was used to quantify SDN (see Supplementary information). Figure $\mathrm{S} 3$ shows the typical product ion spectra of SDN, and the typical chromatograms of SDN detected with the MRM mode of HPLC-ESI-MS/MS are demonstrated in Figure S4. The calibration curve for SDN was generated by linear regression of peak area ratios against the injected amount of the analyte. The curves show good linearity over the calibration ranges in plasma $\left(R^{2}=0.9999\right)$. The $L O Q$, defined as a signalto-noise ratio of 10 , was estimated at $1.2 \mathrm{ng} / \mathrm{mL}$.

The intra- and interday precision and accuracy using the QC samples are shown in Table S1. The precisions (RSDs) are all less than 5\%, and accuracy ranged from $91.7 \%$ to $96.2 \%$ for intraday and $91.0 \%$ to $93.6 \%$ for interday, respectively. This indicates the method is accurate and precise enough to apply in pharmacokinetic study.

The mean recoveries of SDN spikes in plasma at three different concentrations ranged from $91.4 \%$ to $93.6 \%$, and the percentage of RSDs were all less than 7\% $(n=3)$ (see Table S2 for supplementary information), demonstrating that the employed OASIS HLB method for SPE coupled with HPLC-ESI-MS/MS analysis seems to be suitable for detection of SDN in plasma samples. The stabilities of SDN spikes in plasma were studied under different storage conditions including three cycles of freeze-thawing, room temperature for 5 hours, and post-preparation for overnight. The deviation of the mean quantification data was within $5 \%$ in all stability tests for QC samples, and there seems no significant effect $(P<0.5)$ on the quantification of SDN in the plasma samples.

\section{Pharmacokinetics of SDN after oral administration of $V$ iagra ${ }^{\circledR}$ and AEA-coated SDN-MMT to dogs}

Figure 6 shows the mean plasma concentration-time curve of SDN after oral administration of Viagra ${ }^{\circledR}$ and AEA-coated 


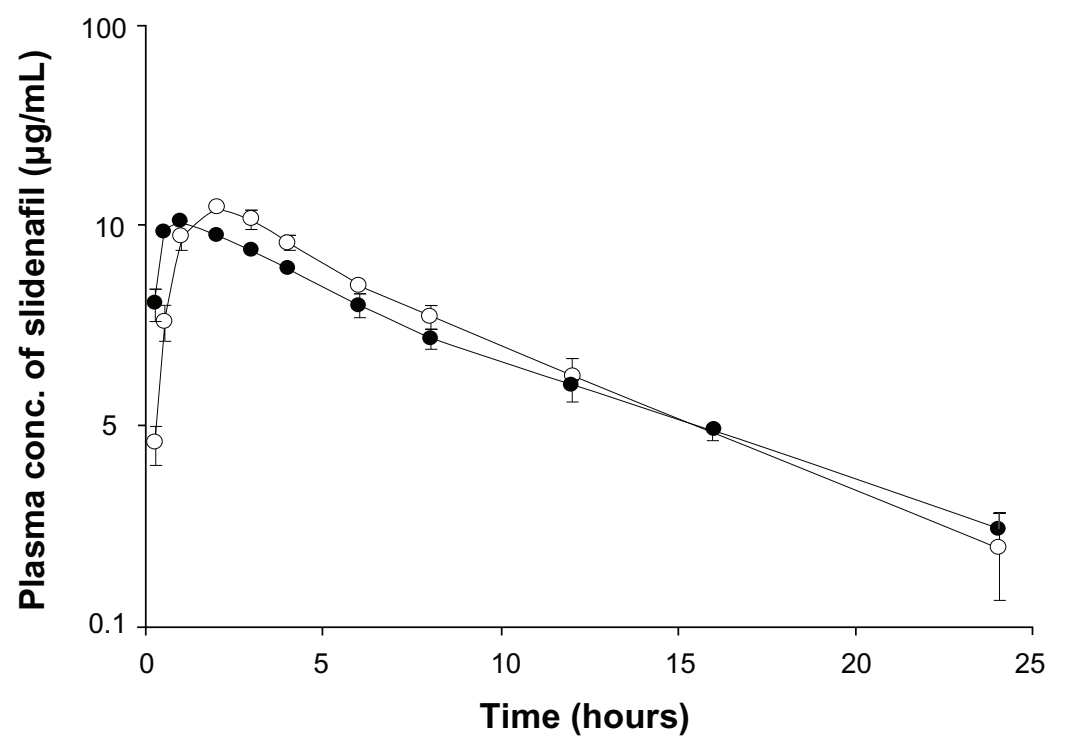

Figure 6 Mean plasma concentration-time curves of sildenafil after oral administration of Viagra ${ }^{\circledR}(\bullet)$ and polyvinylacetal diethylaminoacetate $($ AEA)-coated hybrid $(\circ)$ to the beagle dogs.

SDN-MMT to the beagle dogs. The relevant pharmacokinetic parameters are presented in Table 2. The $\mathrm{AUC}_{0-\infty}$ and $\mathrm{C}_{\max }$ of SDN significantly increased in AEA-coated SDN-MMT nanohybrid compared with Viagra ${ }^{\circledR}(P<0.05)$. Such a difference in drug exposure could be explained by individual pharmacokinetics variability, but the $\mathrm{AUC}_{0-\infty}$ and $\mathrm{C}_{\max }$ values were still statistically meaningful between two groups, even though the number of the animals studied was small $(n=3)$. The increased drug exposure observed in AEA-coated SDNMMT seems to be most likely due to the decreased oral clearance of SDN (4.34 L/hour in Viagra ${ }^{\circledR}$ vs $3.81 \mathrm{~L} /$ hour in AEA-coated SDN-MMT; $P<0.05)$. According to the in vitro drug-release profiles (Figure 5), after the initial burst release $(\sim 80 \%), 10 \%$ of drug was released slowly for the remaining 110 minutes. After 2 hours, the remaining 10\%

Table 2 Pharmacokinetic parameters of SDN after oral administration of Viagra ${ }^{\circledR}$ and AEA-coated nanohybrids to the beagle dogs

\begin{tabular}{lll}
\hline Parameters & Viagra $^{\circledR a}$ & AEA-coated nanohybrid $^{\mathbf{a}}$ \\
\hline $\mathrm{AUC}_{0-\infty}(\mu \mathrm{g} \cdot$ hour$/ \mathrm{mL})$ & $69.2 \pm 3.19$ & $78.8 \pm 2.32^{*}$ \\
$\mathrm{C}_{\max }(\mu \mathrm{g} / \mathrm{mL})$ & $10.5 \pm 0.64 \mathrm{I}$ & $12.4 \pm 0.673^{*}$ \\
$\mathrm{~T}_{\text {max }}$ (hours) & 1.00 & $2.33 \pm 0.577$ \\
$\mathrm{t}_{1 / 2}$ (hours) & $5.00 \pm 0.074$ & $4.13 \pm 0.785$ \\
$\mathrm{~V}_{\mathrm{d}} / \mathrm{F}(\mathrm{L})$ & $31.3 \pm 1.19$ & $22.7 \pm 4.49 *$ \\
$\mathrm{Cl} / \mathrm{F}(\mathrm{L} /$ hour) & $4.34 \pm 0.205$ & $3.8 \mathrm{I} \pm 0.112^{*}$
\end{tabular}

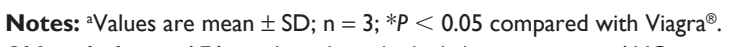

Abbreviations: $A E A$, polyvinylacetal diethylaminoacetate; $A \cup C_{0 . \infty}$, area under the plasma concentration-time curve from 0 hours to infinity; $\mathrm{Cl} / \mathrm{F}$, total clearance; $\mathrm{C}_{\max }$, maximum plasma concentration; $\mathrm{SD}$, standard deviation; $\mathrm{SDN}$, sildenafil; $\mathrm{T}_{\max }$, time required to reach $\mathrm{C}_{\max } ; \mathrm{t}_{1 / 2}$, elimination half-life; $\mathrm{V}_{\mathrm{d}} / \mathrm{F}$, apparent volume of distribution. of drug was still entrapped in the AEA-coated SDN-MMT nanohybrid, which was not released under a simulated in vitro condition. However, many different types of cations possibly present in the living body may continuously replace the entrapped drug molecules to facilitate drug diffusion out. ${ }^{46-48}$ Therefore, the remaining $10 \%$ of SDN would be released in a sustained manner after the nanohybrid passed the gastric cavity. In the intestine, the polymeric barrier of AEA would not be present due to its complete dissolution in a gastric fluid.

Viagra $^{\circledR}$ released almost all drug in 10 minutes, which would allow high systemic absorption at the early stage, resulting in a faster $T_{\max }$ (1 hour), while the absorption of SDN was delayed in the AEA-coated SDN-MMT because the drug entrapped in the interlayer of MMT was released slowly during its passage through the gastrointestinal tract $\left(\mathrm{T}_{\max }=2.33\right.$ hours). For the specific drug, SDN, a faster onset of pharmacodynamic response (ie, a faster $\mathrm{T}_{\max }$ ) would be still desirable. For this reason, our nanohybrid systems need to be further improved to achieve faster drug release at an early stage in addition to taste masking of the drug. In this sense, we envision using more AEA or employing other cationic macromolecules for coating our nanohybrid systems to facilitate deintercalation of the drug and enhance drug release in the gastric cavity. ${ }^{32}$

\section{Stability of SDN}

The drug molecules in nanohybrids could be more sensitive to degradation due to their distribution at a molecular level, 
Table 3 Fraction of nondegraded SDN content in the nanohybrids after incubation under an accelerated stability test condition $\left(40^{\circ} \mathrm{C}, 75 \% \mathrm{RH}\right)$

\begin{tabular}{llllll}
\hline Time (months) & $\mathbf{0}$ & $\mathbf{I}$ & $\mathbf{2}$ & $\mathbf{4}$ & $\mathbf{6}$ \\
\hline SDN-MMT & $\mathrm{I} 00.00$ & $\mathrm{I} 00.06$ & 102.72 & $10 \mathrm{I} .04$ & $\mathrm{I0I.75}$ \\
& $( \pm 0.36)$ & $( \pm 0.4 \mathrm{I})$ & $( \pm 0.45)$ & $( \pm 0.24)$ & $( \pm 0.19)$ \\
AEA-coated & 100.00 & 96.53 & $10 \mathrm{I} .06$ & 96.76 & 99.35 \\
SDN-MMT & $( \pm 0.10)$ & $( \pm 0.23)$ & $( \pm 0.06)$ & $( \pm \mathrm{I} .07)$ & $( \pm 0.34)$ \\
\hline
\end{tabular}

Notes: Values are mean \pm SD; $n=3$ (Unit, \%).

Abbreviations: AEA, polyvinylacetal diethylaminoacetate; SD, standard deviation; SDN-MMT, sildenafil-montmorillonite.

giving a higher chance of interaction with the surrounding environment. Therefore, we assessed the shelf-life of SDN-MMT and AEA-coated SDN-MMT nanohybrids under an accelerated stability test condition (temperature, $40^{\circ} \mathrm{C}$; humidity, 75\%). ${ }^{49}$ As shown in Table 3, the changes in nondegraded SDN content during 6 months were minimal $(< \pm 5 \%)$ for all samples, indicating that the SDN molecules could be well protected in the interlayer space of MMT due to their strong ionic interaction.

\section{Conclusion}

In this study, we suggest nanohybrids as a potential oral disintegrating formulation for delivery of SDN, a drug for treatment of erectile dysfunction. For this purpose, the drug was intercalated into MMT by cation exchange reaction to produce an SDN-MMT nanohybrid for taste masking of SDN. In order to improve the release rate in the simulated gastric fluid, the SDN-MMT nanohybrid was further coated with AEA, a cationic polymer, which exhibited suppressed release under a simulated buccal condition. For in vitro drug release in a simulated gastric fluid, AEA-coated SDN-MMT exhibited relatively fast drug release, ie, $80 \%$ during the first 10 minutes and $10 \%$ during the remaining 110 minutes. However, the total percentage of drug release was about $10 \%$ lower than Viagra $^{\circledR}$. The in vivo pharmacokinetic study revealed that the $\mathrm{AUC}_{0-\infty}$ and $\mathrm{C}_{\max }$ values of SDN were significantly increased with AEA-coated SDN-MMT nanohybrid compared with Viagra $^{\circledR}$. Therefore, we conclude that the nanohybrid system suggested in this work has potential for taste masking of SDN as well as possibly increased drug exposure.

\section{Acknowledgments}

This work was supported by the National Research Foundation of Korea (NRF) (SRC program: 2012-0000650, and WCU program: R31-2008-000-10010-0), the Ministry of Knowledge Economy (10030036) and partly by the Ewha Global Top 5 Grant 2011 of Ewha Womans University.

\section{Disclosures}

Some authors are inventors of a relevant patent. ${ }^{50}$ The authors declare no other conflicts of interest in this work.

\section{References}

1. Choy JH, Kwon SJ, Park GS. High-T superconductors in the twodimensional limit: $\left[\left(\mathrm{Py}_{-} \mathrm{C}_{\mathrm{n}} \mathrm{H}_{2 \mathrm{n}+1}\right)_{2} \mathrm{HgI}_{4}\right]-\mathrm{Bi}_{2} \mathrm{Sr}_{2} \mathrm{Ca}_{\mathrm{m}-1} \mathrm{Cu}_{\mathrm{m}} \mathrm{O}_{\mathrm{y}}(\mathrm{m}=1$ and 2). Science. 1998;280(5369):1589-1592.

2. Choy JH, Kwak SY, Park JS, Jeong YJ, Portier J. Intercalative nanohybrids of nucleoside monophosphates and DNA in layered metal hydroxide. J Am Chem Soc. 1999;121(6):1399-1400.

3. Choy JH, Kwak SY, Jeong YJ, Park JS. Inorganic layered double hydroxides as nonviral vectors. Angew Chem Int Ed. 2000;39(22): 4042-4045.

4. Desigaux L, Belkacem MB, Richard P, et al. Self-assembly and characterization of layered double hydroxide/DNA hybrids. Nano Letters. 2006;6(2):199-204.

5. Kwak SY, Kriven WM, Wallig MA, Choy JH. Inorganic delivery vector for intravenous injection. Biomaterials. 2004;25(28):5995-6001.

6. Choy JH, Jung JS, Oh JM, et al. Layered double hydroxide as an efficient drug reservoir for folate derivatives. Biomaterials. 2004;25(15): 3059-3064.

7. Oh JM, Choi SJ, Kim ST, Choy JH. Cellular uptake mechanism of an inorganic nanovehicle and its drug conjugates: enhanced efficacy due to clathrin-mediated endocytosis. Bioconjugate Chem. 2006;17(6): 1411-1417.

8. Choi SJ, Oh JM, Choy JH. Human-related application and nanotoxicology of inorganic particles: complementary aspects. J Mater Chem. 2008;18(6):615-620.

9. Choi SJ, Choi GE, Oh JM, Oh YJ, Park MC, Choy JH. Anticancer drug encapsulated in inorganic lattice can overcome drug resistance. J Mater Chem. 2010;20(42):9463-9469.

10. Khan AI, Lei L, Norquist AJ, O'Hare D. Intercalation and controlled release of pharmaceutically active compounds from a layered double hydroxide. Chem Commun (Camb). 2001;(22):2342-2343.

11. Williams GR, O'Hare D. Towards understanding, control and application of layered double hydroxide chemistry. J Mater Chem. 2006;16(30):3065-3074.

12. Leroux F, Taviot-Guého C. Fine tuning between organic and inorganic host structure: new trends in layered double hydroxide hybrid assemblies. J Mater Chem. 2005;15(35-36):3628-3642.

13. Kikuchi M, Matsumoto HN, Yamada T, Koyama Y, Takakuda K, Tanaka J. Glutaraldehyde cross-linked hydroxyapatite/collagen selforganized nanocomposites. Biomaterials. 2004;25(1):63-69.

14. Kumar V, Yang T, Yang Y. Interpolymer complexation. II. Entrapment of ibuprofen by in-situ complexation between polyvinyl acetate phthalate (PVAP) and polyvinylpyrrolidone (PVP) and development of a chewable tablet formulation. Pharm Dev Technol. 2001;6(1): $71-81$.

15. Suzuki H, Onishi H, Takahashi Y, Iwata M, Machida Y. Development of oral acetaminophen chewable tablets with inhibited bitter taste. Int J Pharm. 2003;251(1-2):123-132.

16. Azarmi S, Roa W, Löbenberg R. Current perspectives in dissolution testing of conventional and novel dosage forms. Int J Pharm. 2007; 328(1):12-21.

17. Douroumis D. Orally disintegrating dosage forms and taste-masking technologies; 2010. Expert Opin Drug Deliv. 2011;8(5):665-675.

18. Liang AC, Chen LH. Fast-dissolving intraoral drug delivery systems. Expert Opin Ther Patents. 2001;11(6):981-986.

19. Mashru RC, Sutariya VB, Sankalia MG, Parikh PP. Development and evaluation of fast-dissolving film of salbutamol sulphate. Drug Dev Ind Pharm. 2005;31(1):25-34.

20. Cilurzo F, Cupone IE, Minghetti P, Selmin F, Montanari L. Fast dissolving films made of maltodextrins. Eur J Pharm Biopharm. 2008; 70(3):895-900 
21. Singh S, Amin D, Goud M, inventor; Ajanta Pharma Ltd, assignee. Taste masked chewable compositions of sildenafil citrate. Patent Cooperation Treaty WO 09/074995. June 18, 2009.

22. Mapelli LG, Marconi MGR, Zema M, inventor; Eurand International SpA, assignee. Pharmaceutical Formulations. Patent Cooperation Treaty WO 91/016043. October 31, 1991.

23. Sohi H, Sultana Y, Khar RK. Taste masking technologies in oral pharmaceuticals: recent developments and approaches. Drug Dev Ind Pharm. 2004;30(5):429-448.

24. Obeidat WM, Price JC. Preparation and in vitro evaluation of propylthiouracil microspheres made of Eudragit RL 100 and cellulose acetate butyrate polymers using the emulsion-solvent evaporation method. J Microencapsul. 2005;22(3):281-289.

25. Lorenzo-Lamosa ML, Cuña M, Vila-Jato JL, Torres D, Alonso MJ. Development of a microencapsulated form of cefuroxime axetil using pH-sensitive acrylic polymers. J Microencapsul. 1997;14(5): 607-616.

26. Yajima T, Itai S, Takeuchi H, Kawashima Y. Optimum heat treatment conditions for masking the bitterness of the clarithromycin wax matrix. Chem Pharm Bull. 2003;51(11):1223-1226.

27. Xu J, Bovet LL, Zhao K. Taste masking microspheres for orally disintegrating tablets. Int J Pharm. 2008;359(1-2):63-69.

28. Luckham PF, Rossi S. The colloidal and rheological properties of bentonite suspensions. Adv Colloid Interface Sci. 1999;82(1-3):43-92.

29. Eren E, Afsin B. An investigation of $\mathrm{Cu}(\mathrm{II})$ adsorption by raw and acid-activated bentonite: A combined potentiometric, thermodynamic, XRD, IR, DTA study. J Hazard Mater. 2008;151(2-3):682-691.

30. Jung H, Kim HM, Choy YB, Hwang SJ, Choy JH. Itraconazole-laponite: kinetics and mechanism of drug release. Appl Clay Sci. 2008;40(1-4) 99-107.

31. Jung H, Kim HM, Choy YB, Hwang SJ, Choy JH. Laponite-based nanohybrid for enhanced solubility and controlled release of itraconazole. Int J Pharm. 2008;349(1-2):283-290.

32. Park JK, Choy YB, Oh JM, Kim JY, Hwang SJ, Choy JH. Controlled release of donepezil intercalated in smectite clays. Int J Pharm. 2008; 359(1-2):198-204

33. Cai Y, Meng XF, Cao YX, Lu H, Zhu SF, Zhou LZ. Montmorillonite ameliorates hyperthyroidism of rats and mice attributed to its adsorptive effect. Eur J Pharmacol. 2006;551(1-3):156-161.

34. Lin FH, Lee YH, Jian CH, Wong JM, Shieh MJ, Wang CY. A study of purified montmorillonite intercalated with 5-fluorouracil as drug carrier. Biomaterials. 2002;23(9):1981-1987.

35. Goel H, Rai P, Rana V, Tiwary AK. Orally disintegrating systems: innovations in formulation and technology. Recent Pat Drug Deliv Formul. 2008;2:258-274.

36. Baxter JL, Kukura J, Muzzio FJ. Hydrodynamics-induced variability in the USP apparatus II dissolution test. Int J Pharm. 2005;292(1-2): $17-28$.
37. Siewert M, Dressman J, Brown CK, Shah VP. FIP/AAPS guidelines to dissolution/in vitro release testing of novel/special dosage forms. AAPS Pharm Sci Tech. 2003;4(1):E7.

38. Walker DK, Ackland MJ, James GC, et al. Pharmacokinetics and metabolism of sildenafil in mouse, rat, rabbit, dog and man. Xenobiotica. 1999;29(3)297-310.

39. Kuu WY, Chilamkurti R, Chen C. Effect of relative humidity and temperature on moisture sorption and stability of sodium bicarbonate powder. Int J Pharm. 1998;166(2):167-175.

40. Choy JH, Choi SJ, Oh JM, Park T. Clay minerals and layered double hydroxides for novel biological applications. Appl Clay Sci. 2007; 36(1-3):122-132.

41. Stul MS, Mortier WJ. The heterogeneity of the charge density in montmorillonites. Clay Clay Miner. 1974;22:391-396.

42. Yang JH, Han YS, Park M, Park T, Hwang SJ, Choy JH. New inorganic-based drug delivery system of indole-3-acetic acid-layered metal hydroxide nanohybrids with controlled release rate. Chem Mater. 2007;19(10):2679-2685.

43. Dinesh ND, Nagaraja P, Gowda NMM, Rangappa KS. Extractive spectrophotometric methods for the assay of sildenafil citrate (Viagra) in pure form and in pharmaceutical formulations. Talanta. 2002;57(4): 757-764.

44. Melnikov P, Corbi PP, Cuin A, Cavicchioli M, Guimarães WR Physicochemical properties of sildenafil citrate (Viagra) and sildenafil base. J Pharm Sci. 2003;92(10):2140-2143.

45. Elshafeey AH, Bendas ER, Mohamed OH. Intranasal microemulsion of sildenafil citrate: in vitro evaluation and in vivo pharmacokinetic study in rabbits. AAPS Pharm Sci Tech. 2009;10(2):361-367.

46. Barakat NS, Elbagory IM, Almurshedi AS. Formulation, release characteristics and bioavailability study of oral monolithic matrix tablets containing carbamazepine. AAPS Pharm Sci Tech. 2008;9(3): 931-938.

47. Ling G, Zhang P, Zhang W, et al. Development of novel self-assembled DS-PLGA hybrid nanoparticles for improving oral bioavailability of vincristine sulfate by P-gp inhibition. J Control Release. 2010;148(2): 241-248.

48. Jijun F, Xiaoli W, Lishuang X, et al. Preparation and in vitro-in vivo evaluation of double layer coated and matrix sustained release pellet formulations of diclofenac potassium. Int J Pharm. 2011; 406(1-2):84-90.

49. Liu J, Williams III RO. Long-term stability of heat-humidity cured cellulose acetate phthalate coated beads. Eur J Pharm Biopharm. 2002; 53(2):167-173.

50. Choy JH, Lee JH, Park MC, Chang HC, inventor; Daewoong Pharmaceutical Co, LTD, assignee. Sildenafil-bentonite-AEA nanohybrid, pharmaceutical composition containing the same and method for preparing the same. Republic of Korea patent 20110028178. March 17, 2011 


\section{Supplementary information}

Table SI Accuracy and precision of SDN analyses in plasma samples

\begin{tabular}{|c|c|c|c|c|}
\hline \multirow{2}{*}{$\begin{array}{l}\text { SDN } \\
(n=15)\end{array}$} & \multicolumn{2}{|c|}{ Concentration (ng/mL) } & \multirow{2}{*}{$\begin{array}{l}\text { RSD } \\
\text { (\%) }\end{array}$} & \multirow{2}{*}{$\begin{array}{l}\text { Accuracy } \\
\text { (\%) }\end{array}$} \\
\hline & Added & Found (mean \pm SD) & & \\
\hline & \multicolumn{4}{|l|}{ Intraday } \\
\hline & 5.00 & $4.73 \pm 0.19$ & 3.8 & 94.6 \\
\hline & 50.00 & $45.87 \pm 2.32$ & 4.6 & 91.7 \\
\hline & 150.00 & $|44.32 \pm 6.0|$ & 4.0 & 96.2 \\
\hline & \multicolumn{4}{|l|}{ Interday } \\
\hline & 5.00 & $4.55 \pm 0.22$ & 4.4 & 91.0 \\
\hline & 50.00 & $46.31 \pm 2.20$ & 4.4 & 92.6 \\
\hline & 150.00 & $140.40 \pm 6.82$ & 4.5 & 93.6 \\
\hline
\end{tabular}

Abbreviations: SD, standard deviation; SDN, sildenafil; RSD, relative standard deviation.
Table S2 Recovery of SDN spiked into plasma samples

\begin{tabular}{llcl}
\hline $\begin{array}{l}\text { SDN } \\
(\mathbf{n}=3)\end{array}$ & \multicolumn{2}{l}{$\begin{array}{l}\text { Concentration }(\mathbf{n g} / \mathrm{mL}) \\
\text { Expected }\end{array}$} & $\begin{array}{l}\text { Found (mean } \pm \mathbf{S D}) \\
\text { Recovery } \\
(\%)\end{array}$ \\
\hline & 2.00 & $1.83 \pm 0.13$ & 91.5 \\
& 20.00 & $18.28 \pm 1.28$ & 91.4 \\
& 100.00 & $93.62 \pm 6.08$ & 93.6 \\
\hline
\end{tabular}

Abbreviations: SD, standard deviation; SDN, sildenafil.

Table S3 In vitro drug dissolution profiles under a simulated buccal and gastric fluid condition

\begin{tabular}{|c|c|c|c|c|}
\hline \multirow[t]{2}{*}{ Conditions } & \multicolumn{4}{|c|}{$\%$ drug release ${ }^{a}$} \\
\hline & Viagra $^{\circledR}$ & Sildenafil citrate & SDN-MMT & AEA-coated SDN-MMT \\
\hline $\mathrm{pH} 7.0$ & $48.78 \pm 5.49$ & $73.66 \pm 4.61$ & $0.00 \pm 0.00$ & $4.70 \pm 0.53$ \\
\hline \multicolumn{5}{|l|}{ (buccal cavity, } \\
\hline \multicolumn{5}{|l|}{2 minutes) } \\
\hline $\mathrm{pH} \mathrm{I.2}$ & $99.12 \pm 2.55$ & $100.11 \pm 0.22$ & $2.58 \pm 0.26$ & $91.43 \pm 0.69$ \\
\hline \multicolumn{5}{|l|}{ (gastric fluid, } \\
\hline 120 minutes) & & & & \\
\hline
\end{tabular}

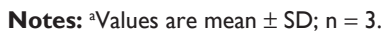

Abbreviations: AEA, polyvinylacetal diethylaminoacetate; SD, standard deviation; SDN-MMT, sildenafil-montmorillonite.

Table S4 Release profiles of sildenafil from (A) SDN-MMT, (B) AEA-coated SDN-MMT, (C) Viagra ${ }^{\circledR}$, and (D) sildenafil citrate. The release experiments were performed at $\mathrm{pH}=1.2$

\begin{tabular}{lllllll}
\hline Samples & \% drug release & & & & \\
\cline { 2 - 6 } & $\mathbf{1 0}$ & $\mathbf{2 0}$ & $\mathbf{4 0}$ & $\mathbf{6 0}$ & $\mathbf{9 0}$ & $\mathbf{1 2 0}$ \\
& minutes & minutes & minutes & minutes & minutes & minutes \\
\hline (A) SDN-MMT & 0.00 & 0.00 & 0.51 & 1.33 & 1.92 & 2.58 \\
& $( \pm 0.00)$ & $( \pm 0.00)$ & $( \pm 0.44)$ & $( \pm 0.06)$ & $( \pm 0.34)$ & $( \pm 0.26)$ \\
(B) AEA-coated SDN-MMT & 78.40 & 84.22 & 87.93 & 89.36 & 90.52 & 91.43 \\
& $( \pm 1.10)$ & $( \pm 0.43)$ & $( \pm 0.51)$ & $( \pm 0.71)$ & $( \pm 0.59)$ & $( \pm 0.69)$ \\
(C) Viagra ${ }^{\circledR}$ & 93.56 & 94.03 & 95.39 & 96.43 & 98.00 & 99.12 \\
& $( \pm 7.60)$ & $( \pm 7.21)$ & $( \pm 5.87)$ & $( \pm 4.73)$ & $( \pm 3.42)$ & $( \pm 2.55)$ \\
(D) Sildenafil citrate & 97.49 & 98.11 & 98.33 & 99.10 & 99.30 & 100.11 \\
& $( \pm 1.06)$ & $( \pm 0.75)$ & $( \pm 0.30)$ & $( \pm 0.45)$ & $( \pm 0.30)$ & $( \pm 0.22)$ \\
\hline
\end{tabular}

Notes: ${ }^{\vee}$ Values are mean $\pm S D ; n=3$

Abbreviations: AEA, polyvinylacetal diethylaminoacetate; SD, standard deviation; SDN-MMT, sildenafil-montmorillonite. 


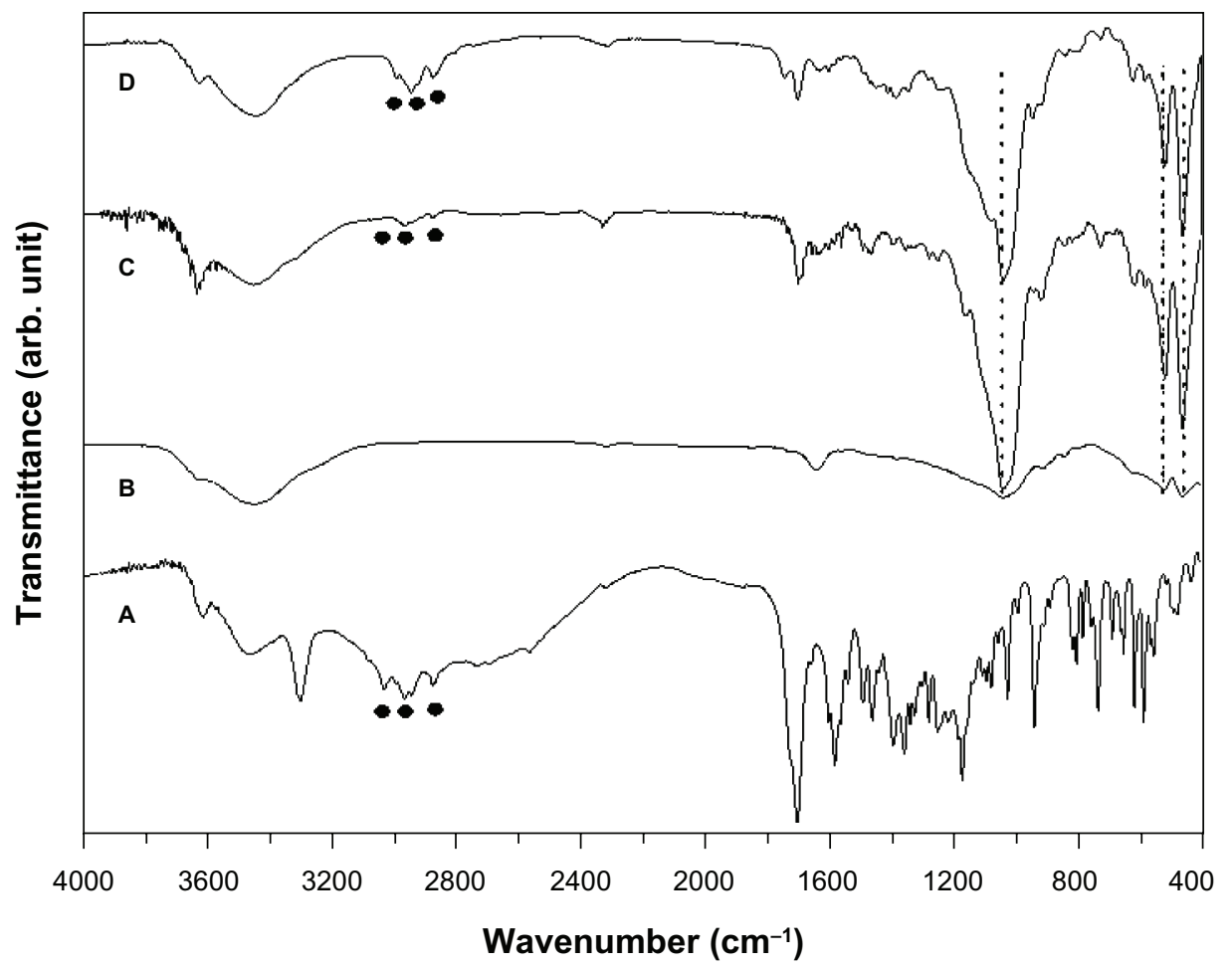

Figure SI Fourier transform infrared spectra of (A) sildenafil citrate, (B) montmorillonite (MMT), (C) sildenafil-montmorillonite (SDN-MMT), and (D) polyvinylacetal diethylaminoacetate (AEA)-coated SDN-MMT.

Notes: The circles $(\bullet)$ and the dashed vertical lines show the characteristic peaks seen with intact SDN and MMT. 

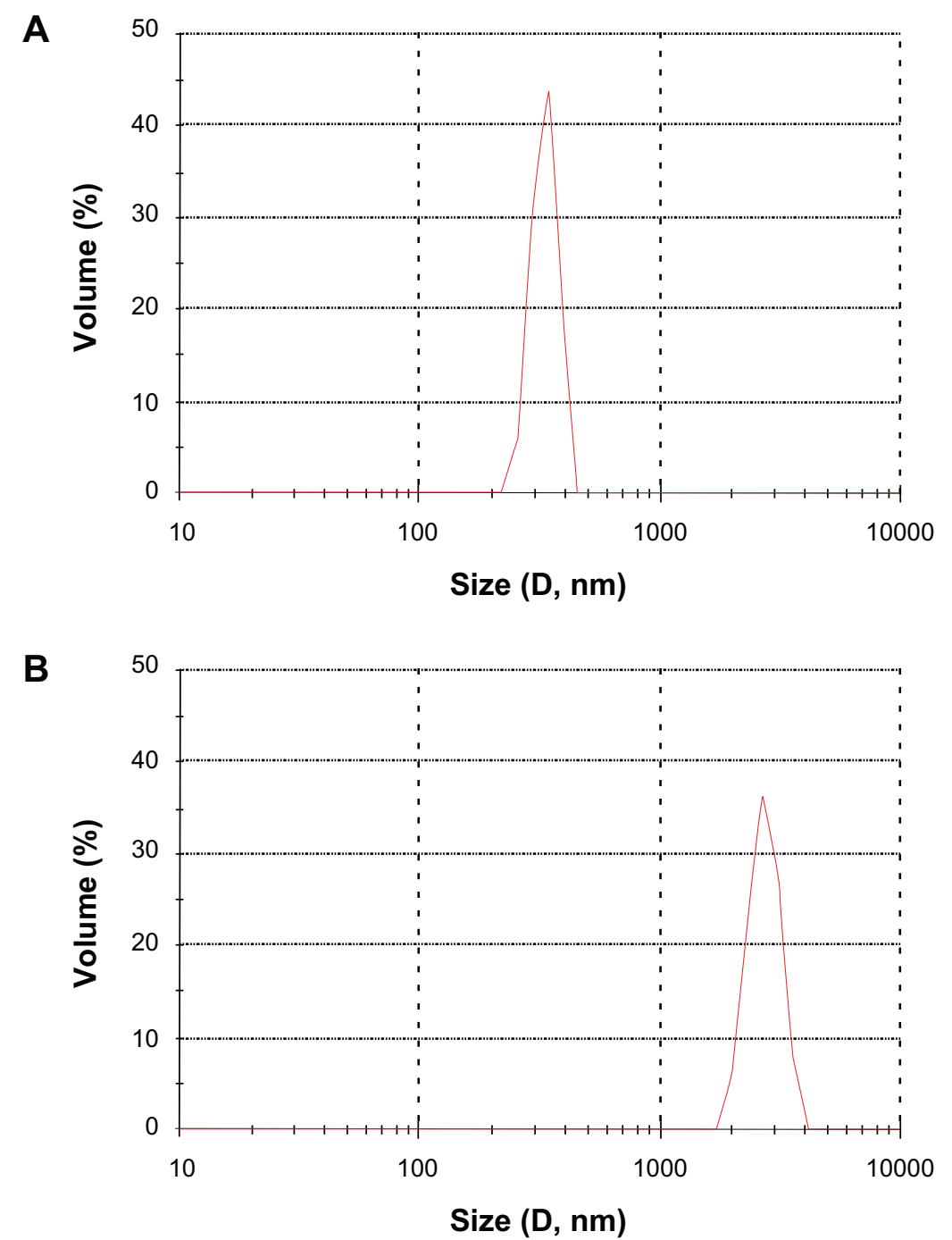

Figure S2 The particle size distribution of (A) sildenafil-montmorillonite (SDN-MMT) and (B) polyvinylacetal diethylaminoacetate (AEA)-coated SDN-MMT.

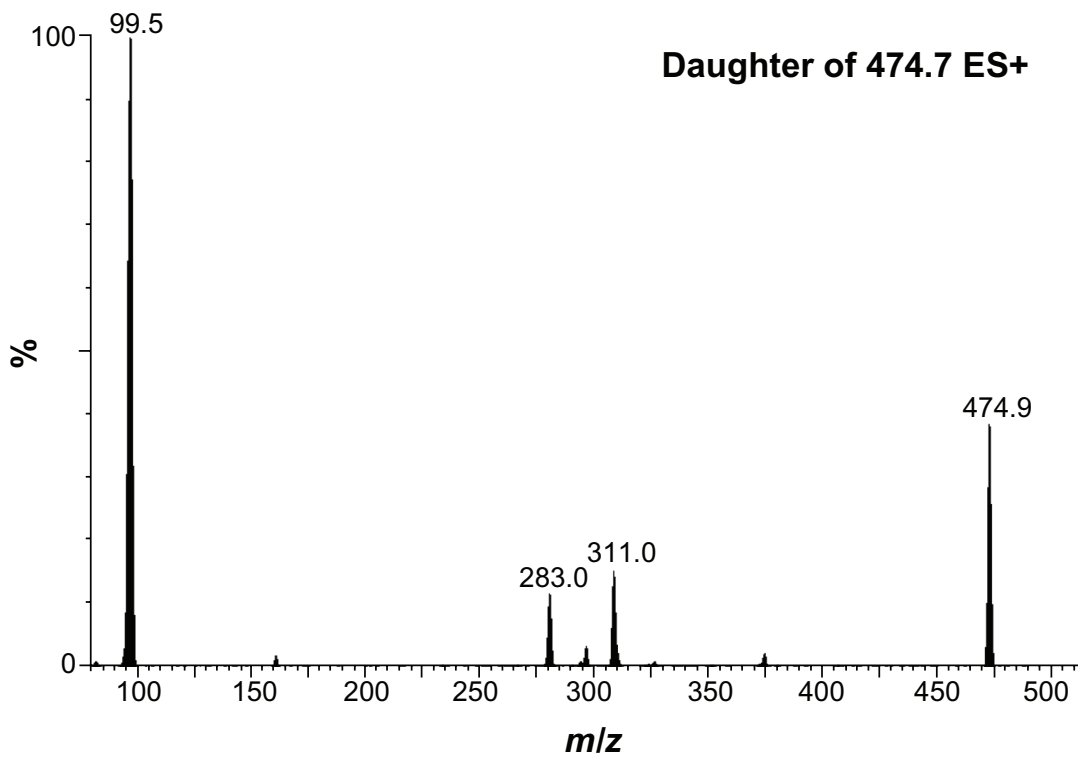

Figure S3 Typical electrospray ionization mass spectrometry/mass spectrometry spectra of authentic sildenafil. 


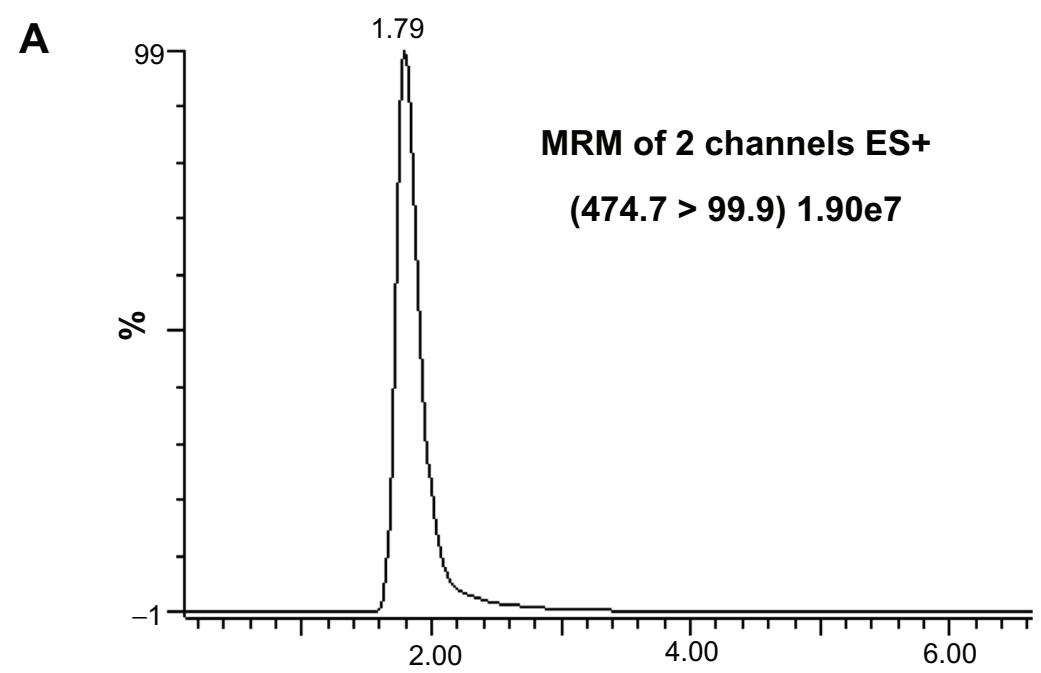

B

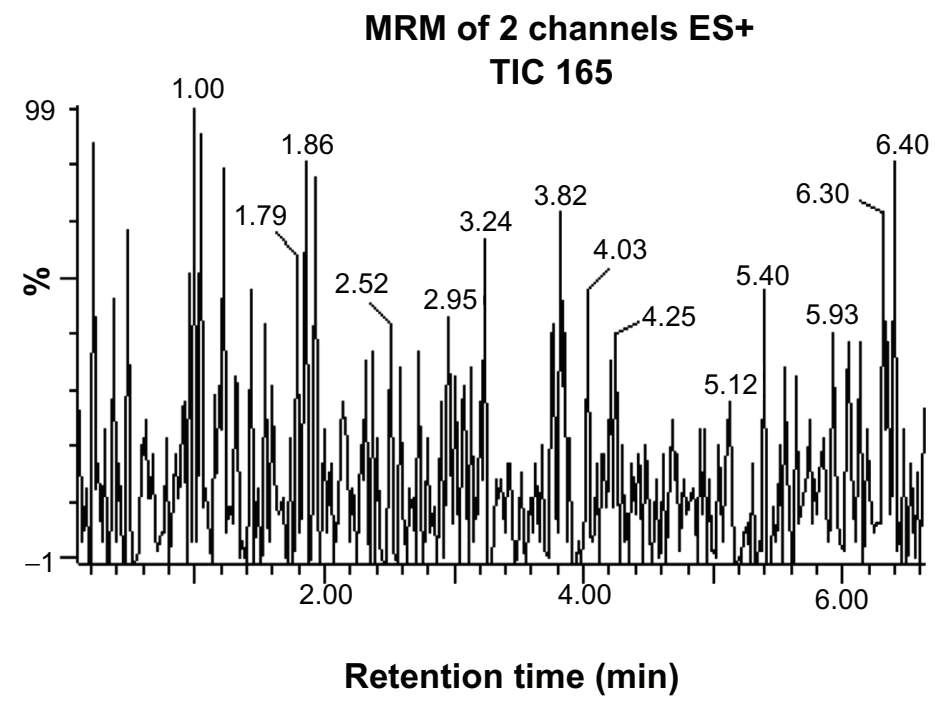

Figure S4 Representative chromatograms of (A) sildenafil detected in a plasma sample collected for 2 hours after sildenafil administration, and (B) blank plasma sample collected just before sildenafil administration.

Abbreviations: ES, electrospray; MRM, multiple reaction monitoring; TIC, total ion count.

International Journal of Nanomedicine

\section{Publish your work in this journal}

The International Journal of Nanomedicine is an international, peerreviewed journal focusing on the application of nanotechnology in diagnostics, therapeutics, and drug delivery systems throughout the biomedical field. This journal is indexed on PubMed Central, MedLine, CAS, SciSearch ${ }^{\circledR}$, Current Contents ${ }^{\circledR} /$ Clinical Medicine,
Journal Citation Reports/Science Edition, EMBase, Scopus and the Elsevier Bibliographic databases. The manuscript management system is completely online and includes a very quick and fair peer-review system, which is all easy to use. Visit http://www.dovepress.com/ testimonials.php to read real quotes from published authors. 